\title{
AS POLÍTICAS DE IRRIGAÇÃO NO NORDESTE: UMA ANÁLISE CRÍTICA.
}

\author{
Iraci Gomes de Vasconcelos Palheta \\ Professor assistente doutor do Departamento de \\ Geografia da FFLCH da Universidade de São Paulo \\ Luiz Carlos Batista, \\ Maria Elisa Miranda e \\ Nelson Giulietti \\ Pós-graduandos do referido departamento
}

\section{1 - Introdução}

O combate aos efeitos das secas, no Nordeste brasileiro, tem sido uma preocupação constante do Estado, desde a época colonial, de modo especial nos momentos em que se define uma situação calamitosa para a agricultura, homens e animais. Entretanto, essa preocupação se tem consubstanciado em medidas paliativas e "soluções" sem resultado. Tais medidas e soluções visam mais minimizar os efeitos das secas do que solucionar as causas fundamentais do flagelo, que o fenômeno acentua e coloca em evidência.

Claro que a seca é um fenômeno natural, que advém de condições climáticas peculiares da Região, em conseqüência de sua posição em relação aos sistemas atmosféricos ali atuantes, traduzindo-se em uma irregular distribuição das chuvas no tempo e no espaço, ou mesmo a ausência delas em um período prolongado de anos. Contudo, não é essa característica climática, que se reflete na paisagem nordestina por condições de semi-aridez (desagregação das rochas, chão pedregoso, vegetação xerofítica e rios temporários) e que afeta a agropecuária da Região, a causa fundamental do flagelo de milhares de nordestinos.
Para se chegar à raiz do problema, algumas questões preliminares devem ser levantadas, tais como: por que as secas continuam a ser um grave problema para o Nordeste? Quem são os mais afetados por elas? Quem se beneficia com as secas e sua "indústria", com as políticas e os programas de combate aos seus efeitos? Por que as políticas ou programas colocados em prática não resolveram os problemas causados pelas secas? A seca é de fato um problema?

Responder a essas questões é buscar a raiz do problema: a questão social do Nordeste. Assim, torna-se necessário revelar, antes de mais nada, quem se apropria do solo, da água e dos outros recursos naturais e, portanto, da riqueza social gerada na Região, para compreender a ação do Estado e, no caso particular, as políticas ou programas de irrigação ali executados.

Os estudos, os programas e os planos de desenvolvimento ou de irrigação para o Nordeste chegam a abordar essas questões, mas, nos momentos de decisão, as medidas propostas não as levam em conta. $\mathrm{E}$ as "soluções" de combate aos efeitos das secas, muitas vezes paliativas e de afogadilho, envolvem concepções de irrigação diferentes e planos mira- 
bolantes e ambiciosos, que redundam - como não poderia deixar de ser - em malogro e engodo para muitos e benefícios para poucos.

Dessa forma, a agricultura tão decantada e defendida nas políticas, planos e programas de irrigação, executados com elevados gastos dos recursos públicos e empréstimos externos, não se desenvolvem segundo as metas propostas.

O setor agrário do sertão vem experimentando mudanças estruturais profundas, seja em razão da expansão agroindustrial, que expropria os pequenos produtores (rendeiros, parceiros, e pequenos proprietários), transformando-os em força de trabalho ou expulsando-os para outras regióes do País, seja pela construção de grandes barragens para produzir a energia elétrica demandada pelos complexos e distritos industriais da Região. A formação de grandes lagos acaba beneficiando as agroindústrias, em detrimento do pequeno produtor que, expulso de suas terras, vai engrossar o exército de reserva nos grandes centros urbanos, ou transforma-se em trabalhador do grande capital agroindustrial, ou ainda produtor de matérias-primas para o mesmo, nos perímetros irrigados, a exemplo do que ocorre no submédio São Francisco, sob a atuação da Codevasf (Andrade, 1983). As práticas agrícolas e as relações familiares de produção parecem combinar com a estrutura ágil e moderna instalada no Sul do País e que se expandiu para o Nordeste.

Dessa forma, os projetos de irrigação propiciam tanto o avanço das forças produtivas e relações de produção tipicamente capitalistas como recriam as condiçôes de reprodução camponesa no semi-árido. Tem servido, sobretudo, à classe dominante de origem urbana, tanto no Nordeste como em outras partes do País. Como a construção de açudes públicos, esses projetos contribuem para concentrar cada vez mais as terras nas mãos de poucos, diminuindo gradativamente as lavouras de subsistência e expulsando o homem do campo.

Fica evidente que as secas não são responsáveis pelos problemas do Nordeste. Elas não determinam a pobreza, mas evidenciam e agravam as causas estruturais dos problemas que afligem o sertão nordestino.

O objetivo deste trabalho é o de chegar ao cerne da questão: a apropriação privada dos recursos terra e água da Região e conseqüentemente da riqueza socialmente produzida nos perímetros e áreas de irrigação.

Evidentemente, não se pretende esgotar um tema tão polêmico e complexo, mas apenas mostrar o sentido contido nas políticas e programas de irrigação no Nordeste; as concepções, objetivos e metas dessas políticas e programas; o volume e a origem dos recursos envolvidos; fazer um balanço entre o pretendido e o realizado em termos da irrigação e do desenvolvimento da agricultura irrigada; discutir as intenções contidas nos documentos oficiais e mostrar quem se beneficia com a execução desses programas.

\section{2 - Atuação do Estado ante o problema das secas: antecedentes históricos}

Apesar do conhecimento da ocorrência de secas desde o século XVI, foi somente a partir do século XIX, durante o Império, que as autoridades, preocupadas com as graves conseqüências da grande seca de 1877-1879, começaram efetivamente a tomar medidas para o combate aos efeitos daquelas.

No final de 1877 , diversas reuniões foram promovidas pelo Instituto Politécnico do Rio de Janeiro, quando engenheiros, presididos pelo Conde d'Eu, apresentaram sugestōes para diminuir os efeitos das secas, dentre elas: 1) construir, quanto antes, no Interior da Província do Ceará e em outras assoladas pela seca, represas nos rios e açudes; 2) ativar ou executar, para dar trabalho e salários à população atingida pela seca, a construção de vias ferreas, obras de melhoramento nos portos marítimos e fluviais, construção de linhas telegráficas gerais e desapropriação de terras marginais às vias ferreas, para serem divididas pelos retirantes ou colonos nacionais.

O Governo Imperial nomeou uma comissão para implementar essas sugestões, a qual foi incumbida também de percorrer o Ceará e estudar os meios práticos de abastecimento de água suficiente às necessidades da populaçăo, manutenção do gado e estabelecimento de um sistema de irrigação que viabilizasse a cultura das terras.

A Comissāo, em viagem ao interior do Ceará no início de 1878, propôs as seguintes medidas: 1) 
construção das ferrovias de Baturite, Comocim a Sobral e Aracati a Ico; 2) construção de trinta açudes, com capacidade de armazenamento de um milhão de metros cúbicos d'água; 3) construção de estações meteorológicas; 4) construção de canal ligando os rios São Francisco e Jaguaribe. Apesar do trabalho desenvolvido pela Comissão, a mesma foi extinta em junho de 1878 .

Em 1880 novos estudos foram realizados e proposta a construção dos seguintes açudes: Itacolomi, Lavras e Quixadá, todos no Ceará. A construção do Cedro I (antigo Quixadá) foi iniciada em 1884 e paralisada dois anos depois. Reiniciada, em virtude da seca de $1888-89$, sua construção só terminou em 1906 , ou seja, doze anos após seu início.

No Governo Rodrigues Alves, a lei orçamentária destinou uma parcela ao combate às secas e seus efeitos, sendo criadas três comissões: "Açudes e Irrigação" sediada no Ceará, "Estudos e Obras Contra os Efeitos das Secas" e "Perfuração de Poços", sediadas no Rio Grande do Norte.

Em 1906, no Governo Afonso Pena, as três comissōes fusionaram-se e transformaram-se na "Superintendência de Estudos e Obras Contra os Efeitos das Secas", logo após tornada sem efeito e restabelecida a Comissão de Açudes e Irrigação.

Esses 6rgãos praticamente nada realizaram, além de estudos de açudagem e drenagem.

Em 1909, no Governo Nilo Peçanha, foi criada a Inspetoria de Obras Contra a Seca (IOCS), com muitas atribuições, mas nenhuma de irrigação. Em 1911, outro decreto deu caráter permanente a IOCS.

Foi no Governo Epitácio Pessoa que esse órgão passou a dispor de mais recursos para as obras na Região. Como nordestino, o presidente dirigiu a ação do Estado mais para sua Regiāo e, assim, logo no início de seu governo (1919) o órgão de combate às secas passou a chamar-se Inspetoria Federal de Obras Contra as Secas (IFOCS). Nesse mesmo ano a Lei "Epitácio Pessoa" regulamentou a construção de obras para irrigação, destinando para esse fim, em 1921-22, $15 \%$ da receita total da União.

Nos governos seguintes voltaram a escassear as verbas para a Região, pois os mesmos não viam as secas no Nordeste como um problema nacional. Essa situação só veio modificar-se com a Revolução de 1930. Em 1931 a IFOCS teve suas atribuiçôes redefinidas, priorizando a construção da grande açudagem para a irrigação.

A partir de 1934, o combate às secas e seus efeitos passou a ser constitucional, e a União deveria elaborar e obedecer um plano sistemático e permanente de obras e serviços de assistência técnica aos flagelados, despendendo para isso quantia não inferior a $4 \%$ da sua receita tributária sem aplicação especial.

Em 1936, o Governo Getúlio Vargas criou, através de lei, o Polígono das Secas, cuja área corresponde a $52 \%$ da área total do Nordeste.

No final de 1945, mediante Decreto-Lei, a IFOCS foi transformada em Departamento Nacional de Obras Contra as Secas (DNOCS). A Constituição de 1946 também assegurava a dotação de recursos para as obras contra as secas.

A política oficial posta em prática, até então, era a construção de açudes para armazenar água. Essa política ficou conhecida como política de acumulação de água ou "fase da engenharia hidráulica", que durou 60 anos. Foi somente a partir do fim da década de 60 que começou efetivamente a ser delineada uma política de irrigação no Nordeste, com a criação, em 1968, do Grupo Executivo para a Irrigação e o Desenvolvimento Agrícola (GEIDA).

\section{3 - Balanço das políticas de irrigação recentes}

Para fazer um balanço geral da política de irrigação no Nordeste, é necessário analisar as intençöes contidas nos documentos oficiais e os resultados reais dos programas e projetos, tanto no nível do fortalecimento da economia da Região, como no dos benefícios para a população vitimada pelas secas.

A questão da irrigação no Nordeste, desde 1970 , com a divulgação do Plano Nacional de Irrigação, é enfocada numa perspectiva de estratégia nacional. Em 1971, o Programa Plurianual de Irrigação (PPI) estabelecia metas ate 1980. O Grupo Executivo para a Irrigação e o Desenvolvimento Agrícola (GEIDA), criado em 1968, procurou com o PPI traçar as 
diretrizes de uma política de irrigação, além de analisar projetos isolados. Considerou que $1 / 3$ da área total do País era apta a desenvolver projetos de irrigação. Deste total fazia parte o Nordeste juntamente com o Leste, Sudeste e Sul.

O Nordeste foi subdividido em duas sub-regiões, sendo que o Vale do Rio São Francisco destacou-se do conjunto nordestino em virtude de suas potencialidades específicas, ficando subordinado às responsabilidades extensivas de dois orgãos distintos: o DNOCS (Departamento Nacional de Obras Contra as Secas) e a CODEVASF (Companhia de Desenvolvimento do Vale do São Francisco).

A partir de 1972, a política de irrigação no Nordeste tinha como meta irrigar 40 mil hectares até 1974, conforme as linhas mais gerais do I PND (Plano Nacional de Desenvolvimento) e tendo como fonte de recursos parte da arrecadação dos incentivos fiscais. Os resultados quantitativos desta política ficaram muito aquém das metas propostas em termos de área irrigada, criação de empregos e produção agrícola.

A partir do II PND, metas ambiciosas foram novamente fixadas para o período 1975-79 (mesmo não tendo atingido a meta anterior traçada), sendo que, para as áreas de atuação do DNOCS e CODEVASF, a irrigação deveria atingir $225 \mathrm{mil}$ hectares ate 1979.

O PPI é o documento definidor da política de irrigação até 1979, juntamente com o próprio texto do II PND, além dos detalhamentos realizados pela SUDENE (Superintendência do Desenvolvimento do Nordeste) como orgão supervisor de toda a política econômica do Governo Federal na Regiẫo.

Os documentos elaborados, entretanto, não explicitavam os objetivos gerais desta política, supondo-se que os objetivos delineados pelo PPI continuam a ser considerados na globalidade das ações e projetos da política nacional de irrigação (PNI).

De qualquer forma, há uma indefinição de objetivos nesta etapa da política de irrigação e uma incoerência quanto às metas dos vários documentos. Por exemplo, o DNOCS declara em 1976 a meta de 60 mil hectares de superfície agrícola útil irrigada; já a CODEVASF estipula o total de $165 \mathrm{mil}$ hectares. No detalhamento que a CODEVASF fez do II PND, a meta é 205 mil hectares, embora a soma das áreas nos projetos seja de apenas $175 \mathrm{mil}$.

Quanto às metas de criação de emprego, elas refletem a confusão e inconsistência na fixação da área irrigada, além das estimativas, tanto da Codevasf quanto do DNOCS, revelarem um otimismo não-realista. Os dois órgãos, juntos, esperavam implantar 225 mil hectares irrigados ate 1979, o que propiciaria a criação de 303 mil empregos.

Com relação à elevação da renda, que se constituía num dos objetivos básicos do II PND, nenhuma meta foi fixada.

O Programa de Desenvolvimento das Áreas Integradas do Nordeste (POLONORDESTE), principal fonte de recursos do Programa de Integração para o Nordeste, sendo responsável por $88,5 \%$ das aplicações da CODEVASF em 1976; o PIN (Programa de Irrigação Nacional), mais recentemente, é a segunda maior fonte de recursos do Programa de Irrigação do Nordeste. Essas duas fontes, contudo, não foram suficientes para prover o Programa com os recursos deste, previstos no Plano, o que explica em parte a não-consecução das metas propostas.

O confronto entre metas e realizaçōes fornece um quadro alarmante: a área-meta a ser irrigada era de 225 mil hectares, sendo que, até 1976, a área efetivamente irrigada foi de aproximadamente 17,5 mil hectares, ou seja, apenas $7,8 \%$ da meta proposta para 1979 , restando ainda, para os 3 anos do período de vigência do II PND, mais de $90 \%$ dela a ser cumprida.

Os resultados quanto ao assentamento de famílias, menos de $28 \%$ da meta do DNOCS e apenas $11 \%$ da meta da CODEVASF, haviam sido atingidos em 1976.

O não-cumprimento dessas metas não pode ser creditado à escassez de recursos, pois, até 1976, já haviam sido liberados mais de $80 \%$ dos recursos previstos. Este fato leva a crer que os custos da irrigação foram subestimados nos projetos e que com os cortes parciais dos recursos ou desvios dos mesmos produziu esse quadro decepcionante.

A respeito do impacto da política de irrigação sobre o número de empregos no Nordeste semi-ári- 
do, temos que considerar que os dados oficiais sobre "criação" de empregos não consideram a destruição de empregos existentes antes da instalação dos projetos, fato extremamente significativo no Nordeste, e que as estatísticas oficiais não revelam.

Além disso, os dados de empregos criados referem-se somente a empregos diretos; seria necessário adicionar a simultânea criação de empregos indiretos.

Na verdade, os efeitos do Programa de Irrigação para o Nordeste foram pequenos e conseguidos às custas de uma considerável aplicação de recursos públicos. É o que ressalta Maia: "A comparação entre a relação capital/trabalho que se verifica neste programa e os padrões internacionais observados nas políticas de irrigação apontam para um estranho fenômeno: numa região caracterizada pela disponibilidade de trabalho, uma política supostamente destinada a melhorar as condições de emprego adota métodos intensivos em capital quando tecnologias alternativas, em princípio, parecem estar disponíveis. Estranho fenômeno, ressalve-se, considerando a disponibilidade relativa dos fatores. Nada estranho, entretanto, em confronto com o estilo de política de desenvolvimento regional" (Gustavo Maia Gomes, 1979:436).

Pode-se, assim, concluir que a política de irrigação tem destruído mais empregos do que os tem criado, tem penalizado as camadas mais pobres do sertão nordestino com expulsões e desapropriaçōes, não levando em conta os interesses e aspirações do homem do campo.

As metas não-atingidas, de renda e produção, revelam o fracasso dos programas, que são incapazes de pagar os próprios investimentos neles feitos, e o reduzido impacto sobre a economia regional.

Estudo realizado pelo Centro de Ciências Agrárias da UFCE (1986) faz estimativas das taxas de crescimento de algumas variáveis como renda e produtividade agrícola nos seguintes perímetros de irrigação: Lagoas do Piauí (PI), Morada Nova (CE), Ico-Lima Campos (CE), Curu-Paraipoba (CE), Săo Gonçalo (PB), Moxotó (PE) e Vaza dos Barris (BA).

Embora não se tenha informações sobre a ex- pansão do número de irrigantes no período de 1977/84, verifica-se que os perímetros estudados apresentaram de modo geral um crescimento da área irrigada, com exceção do perímetro Vaza dos Barris (BA).

Quanto à análise de rendimentos físicos por hectare, das principais culturas, nesses perímetros, constata-se que, de modo geral, os rendimentos se apresentam mais elevados do que aqueles observados a nível de Nordeste e Brasil, mas que esses rendimentos dentro de cada perímetro vão apresentar algumas reduções significativas de produtividade em certas culturas. Tal é o caso do feijão, milho, algodão e tomate.

O estudo citado identifica fatores negativos que impossibilitam o crescimento dos rendimentos das culturas exploradas nessas áreas irrigadas como: desgaste de obras e equipamentos com a parcial desativação das áreas irrigadas; infra-estrutura física de irrigação e drenagem em estado precário, sem manutenção adequada, em virtude da escassez de recursos; deficiência de assistência técnica aos irrigantes e problemas de crédito, que é insuficiente e que chega com atrasos aos irrigantes.

Quanto à renda líquida por irrigante ou por família, variável de alta relevância, foi feita uma comparaçāo do poder de ganho líquido dos irrigantes, em termos reais, com o salário mínimo regional, e depois se comparou a renda líquida anual, com a renda per capita do setor rural, do Nordeste.

Na primeira comparação estabelecida, que aliás se cerca de grande limitação, verificou-se que as rendas auferidas pelos irrigantes de cada perímetro estudado foram relativamente superiores ao salário mínimo da Região naquele ano.

Na segunda comparação, verificou-se que os perímetros não apresentaram um quadro homogêneo, sendo alguns mais eficientes que outros. Por exemplo os de Curu-Recuperação e Curu-Paraipoba (CE) e Vaza dos Barris (BA), por causa do apoio agroindustrial, apresentaram posição relevante $\mathrm{em}$ relação aos demais. Nos perímetros voltados para culturas como algodão, feijão, milho e arroz, subordinados a um sistema expropriador de comercialização, a renda apresentou-se instável e decrescente. 
Em 1986, o Governo Federal lançou o Programa de Irrigação do Nordeste (PROINE), que possui metas mais ambiciosas que os anteriores, prevendo irrigar uma área de 1 milhão de hectares, em cinco anos, com recursos da ordem de 4,3 bilhões de dólares. Contudo, não tivemos oportunidade de manusear o programa, razão pela qual não faremos a avaliação do mesmo.

\section{4 - Avaliação das políticas de irrigação e perspec- tivas atuais}

A análise dos planos e do Programa de Irrigação do Nordeste demonstra um enorme hiato entre o discurso e a prática. Tais planos e Programa visavam a criação de emprego, elevação dos níveis de renda da população e da produção agrícola. Efetivamente o que ocorreu foi uma elevação da produção "comercial" nos perímetros irrigados.

A política de irrigação implementada tinha, paradoxalmente enquanto discurso, a intenção de atuar em favor da coletividade e uma prática que beneficiou os grandes proprietários de terras, detentores do poder político na Região, ou aos donos do capital dispostos a monopolizar a terra. De início, essa prática foi desenvolvida pelo IFOCS e atual DNOCS, que construíram açudes públicos dentro dos grandes latifúndios.

Uma verdadeira política de irrigação deveria prever a desapropriação das terras localizadas nas bacias de irrigação com a conseqüente distribuiçăo, assistência técnica e crédito acessível às famílias camponesas que as ocupavam. Isso significaria uma reforma agrária nas regiōes proximas aos açudes, o que implicaria na desestabilização do poder político e económico dos grandes proprietários. Nas condições dadas, isso era impossível de ser realizado pelo IFOCS/DNOCS.

A prática adotada pelos órgãos públicos não era destinada a resolver o problema social do Nordeste, nem a distribuir a terra, nem a criar empregos diretos ou indiretos, através da irrigação. Essa prática visava a concentração de terras e a reprodução do capital, expulsão de camponeses, provocando êxodo rural e agravando ainda mais a situação de miséria na Região.

Por outro lado, a política de irrigação desenvol- vida pela CODEVASF, no Vale do Rio São Francisco, veio favorecer os latifundiários e as grandes empresas nacionais e multinacionais, as cooperativas capitalistas e, mais recentemente, as grandes usinas produtoras de açúcar e álcool.

Desse modo, vem se promovendo a transformação/integração da agricultura sertaneja ao mercado capitalista, com a criação de infra-estrutura, incentivos e aval do Estado. Os resultados das políticas de irrigação evidenciam essa tendência através dos efeitos contrários sobre a criação de empregos no campo, na medida em que destrói milhares de empregos com as desapropriações, liberando força de trabalho para a indústria ou criando o "exercito de reserva", marginalizado nos grandes centros urbanos. No campo abriu-se, assim, um caminho para a modernização "conservadora" e expansão do capital na agricultura e recriou-se um tipo novo de subordinação da renda ao capital, pela forma de circulação da mercadoria que se estabelece no perímetro de irrigação, alterando as práticas tradicionais: como as feiras, os ambulantes e os intermediários.

Modernas unidades de produção para o beneficiamento de matéria-prima, produzida nos perímetros irrigados, instalaram-se junto aos grandes projetos de irrigação no Vale do São Francisco, a exemplo da Cica Norte e da Peixe, subordinando os pequenos irrigantes. $O$ processo de subordinação se dá desde o fornecimento de insumos, para atender à importação de tecnologia e aos compromissos internacionais (com graves conseqüências ambientais), até o transporte e financiamento à produção, impossibilitando outro tipo de comercialização, que não com as agroindústrias e cooperativas aí localizadas.

Por outro lado, o Nordeste importa grande parte dos produtos alimentícios que consome e certamente as causas não são somente as secas, mas estas são evidenciadas com a concentração da propriedade da terra, que propicia ao mesmo tempo lucro e renda às empresas capitalistas, no cultivo de produtos não-essenciais aos habitantes locais.

Tais críticas dizem respeito à política de irrigação adotada no Nordeste; isto não quer dizer que a irrigação não seja viável e necessária. Entretanto, a política adotada, principalmente a partir de 1970 , 
não tem atendido às demandas sociais, mas está voltada ao crescimento económico, aos interesses privados (nacionais e internacionais), tornando o País viável para o capital e sua expansão e, em última análise, como forma de conseguir recursos do Exterior (entendidos como necessários ao desenvolvimento econômico e social do País) para viabilizar essa expansão.

\section{5 - Conclusões}

Pode-se destacar alguns aspectos do processo político designado por Programa de Irrigação no Nordeste. Um deles diz respeito ao modelo econômico adotado, voltado para a industrialização, a partir de investimentos estrangeiros, alicerçado em uma tecnologia importada e em uma ideologia de "segurança nacional" (subentendida como segurança para o capital).

Outro diz respeito ao planejamento, que transformou-se no instrumento fundamental da expansão capitalista, desprezando-se os mínimos anseios da maioria da população. Dessa forma, interesses e os grandes e ambiciosos projetos, ainda que inviáveis na prática, foram suficientes para viabilizar a consecução de vultosos empréstimos pelos bancos e organismos internacionais, aumentando a dívida externa e realimentando, a cada iniciativa frustrada, novos projetos e programas, como forma de garantir a linha de crédito.

A política atual de irrigação no Nordeste continua demonstrando que os incentivos estão tendo os mesmos destinatários, ou seja, os fazendeiros que habitam a cidade. No caso dos pequenos pro- dutores, eles continuam mal-informados e sem acesso ao crédito, em virtude, em parte, do excesso burocrático exigido para obtê-lo, além da dificuldade que o homem do campo tem para compreender seus mecanismos, causando-lhe embaraços nas relações com as agências financiadoras estatais ou privadas. Isto se deve, também, à falta de escolarização na zona rural onde existe um elevado e sintomático nível de analfabetismo.

A análise das perspectivas atuais exige, como princípios, procedimentos relacionados a uma séria política educacional que democratize o acesso à escola, e uma escola voltada aos interesses e ao ciclo produtivo do lavrador.

A reforma agrária também se situa como um processo dinâmico de conscientização do homem do campo, a partir das práticas educativas integradas, possibilitando-lhe definir sua própria "política" de irrigação. A reforma agrária é antes de tudo indispensável para diminuir as dificuldades sociais que marginalizam o homem rural, submetendo-o à pobreza absoluta, sobretudo no Nordeste onde se situam os maiores índices de concentração da terra.

Finalmente, torna-se necessário redirecionar a política de industrialização do País (da qual o Nordeste representa o quadro mais vivo dessa realidade), a fim de possibilitar a elevação dos níveis de vida de seus habitantes, sobretudo daqueles ocupados nas atividades agropecuárias regionais. Distinguir que tipo de indústria deverá ser incentivado, destinado a implementar o desenvolvimento socioeconômico da região.
The denaturalization of the Brazilian "Nordeste" is the aim of this paper. The private appropriation of socially produced resouces and wealth in irrigated areas and primeters with the state support by means of political programs of irrigation is discussed. It also points out the deep transformations suffered by the agrarian areas in the "sertāo" because of the expansion of agro-industries; small-property producers

\section{BSTRACT}

turn into workers for the capital, or migrate to other regions where they reproduce themselves or increase the industrial reserve army in big urban centers. Finally, this paper recovers the struggle agaist drought consequences, offers a balance of recent irrigation politics and evaluates them critically.

\section{BIBLIOGRAFIA}

ANDRADE, Manual Correira de. Tradição e mudança: a organização do espaço rural e urbano na área de irrigação do Submédio São Francisco. Rio de Janeiro. Zahar, 1983.
ANDR/2DE, Manual Correira de. Classes Sociais e agricultura no Nordeste. Recife. FUNDAJ, Editora Massangana, 1985. 
AZEVEDO, Roberto et alii. Estudo do comportamento de renda e da produtividade agrtcola dos principais pertmetros do Nordeste sob a jurisdição do DNOCS, 1977-1984. Fortaleza, 1986. Centro de Ciências Agrárias, Departamento de Economia. (Série Pesquisas $n \div 45$ ).

CARNEIRO, Joaquim Osterne. DNOCS: organismo pioneiro no estudo e equacionamento dos problemas do Nordeste Semi-Árido. Fortaleza, 1981. Ministerio do Interior, DNOCS.

CASEMIRO, Liana Maria C. de. " $A$ seca. momento para repensar a pobreza no Nordeste" (uma análise a partir do Estado do Ceara). Fortaleza, 1984. Federação das Indústrias do Estado do Ceará, Instituto Euvaldo Lodi.

COELHO, Jorge. Imigação no Nordeste brasileiro e tecnologia para Trópico Semi-Arido. uma abordagem sobre técnicas de manejo dos recursos naturais renovaveis e algumas implicaçöes socio- económicas. s.n.t. (mimeo.). Palestra realizada no Instituto Joaquim Nabuco de Pesquisas Sociais. Recife, 1982.

EISEMBERG, Peter. Modernização sem mudança. Rio de Janeiro. Paz e Terra, 1977.

FERREIRA IRMÃO, José. Impacto dos investimentos nos programas de irrigação e Proterra. Revista de Economia Rural. Brasília. 19 (3):537-564, jul.-set., 1984.

GOMES, Gustavo Maia. Política de irrigação no Nordeste: intençōes e resultados. Pesquisa e Planejamento Econômico, Rio de Janeiro, $9(2): 411-446$, ago. 1979.

BRASIL, MINISTÉRIO DO INTERIOR/SUDENE. Uma polftica de desenvolvimento económico para o Nordeste. 2' Edição. Recife, 1967.

SAN MARTIN, Paulo. Agricultura suicida, um retrato do modelo brasileiro. Icone, São Paulo, 1985. 